this high-risk population compared with $8 \%$ for matched classroom full-term controls. Motor assessment at 3 years of age using Peabody Fine Motor Scales is highly predictive of subsequent DCD at school age. Early identification of DCD allows early intervention to prevent school problems and loss of self-esteem. Differences in the prevalence rates of DCD in various reports could be explained by different methods of measurement. The incidence of ADHD, commonly complicated by DCD, in these cohorts would be of interest.

\title{
PRESENTING SYMPTOMS OF CHIARI TYPE I MALFORMATION
}

Clinical and radiographic predictors of neurologic symptoms were investigated in a population-based retrospective study of 51 children identified with Chiari I malformation at the University of California, and Kaiser Department of Radiology, San Francisco. The patients represented $1 \%$ of children who had head or spine MRI during the study period, 1997-1998. The mean age at diagnosis was 11 years. Tonsillar ectopia ranged from 5 to 32 $\mathrm{mm} ; 22 \%$ were $>10 \mathrm{~mm}$. Cerebellar tonsils were abnormally pointed in $55 \%$ of cases, with CSF compression in $57 \%$. Syringomyelia occurred in $6(12 \%)$ of the Chiari I patients. Nineteen (37\%) patients were diagnosed incidentally, MRIs performed for atypical symptoms such as seizures and scoliosis.

Of the 51 patients, $32(63 \%)$ had symptoms at diagnosis. Headache was the most common presenting complaint, occurring in $28(55 \%)$ patients, neck pain in $12 \%$, vertigo $(8 \%)$, sensory changes $(6 \%)$, and ataxia or incoordination $(6 \%)$. Other symptoms at time of diagnosis included leg weakness, tinnitus, hearing loss, dysarthria, loss of consciousness and scoliosis with syrinx, each occurring in 1 patient. Patients were followed for a mean of 6.4 years, and headache was the most common complaint, occurring in $61 \%$ of the 51 patients during the study period. Headache was moderate or severe and required frequent follow-up. Of 3 who had suboccipital decompression surgery for intractable daily headaches, 2 had complete resolution for up to 7 years of follow-up, and 1 relapsed after 12 months.

Older age at diagnosis was predictive of headache occurrence, while none of the radiological characteristics, including degree of ectopia, were associated with headache or other neurologic symptoms. Half of all children with Chiari I (49\%) had significant neurologic symptoms. Borderline tonsillar ectopia $(2-4 \mathrm{~mm})$, in 19 patients $(0.4 \%$ of all head and spine MRIs), although considered a normal variant, was associated with headache in $74 \%$, severe in $16 \%$. Occipital headache occurred in $11 \%$. None of the borderline cases showed pointed tonsils or retrocerebellar CSF compression $(\mathrm{P}<0.0001)$. (Aitken LA, Lindan $\mathrm{CE}$, Sidney S, et al. Chiari type I malformation in a pediatric population. Pediatr Neurol June 2009;40:449-454). (Respond: Dr Wu, UCSF Division of Child Neurology, 350 Parnassus, Suite 609, San Francisco, CA 94117. E-mail: wuy@neuropeds.ucsf.edu).

COMMENT. Headache is a frequent presenting symptom of Chiari I malformation in children, but the malformation is often discovered incidentally in children without characteristic symptoms. Although $5 \mathrm{~mm}$ of tonsillar ectopia is the accepted cutoff for the diagnosis of Chiari I, patients with lesser degrees of ectopia may also develop typical symptoms and syringomyelia. 